\title{
Detection of Helicobacter pylori in stool specimens by non-invasive antigen enzyme immunoassay in children: multicentre Italian study
}

\author{
Giuseppina Oderda, Anna Rapa, Barbara Ronchi, P Lerro, Maria Pastore, Annamaria Staiano,
} G L de'Angelis, P Strisciuglio

Helicobacter pylori infection is mainly acquired in childhood and may predispose to peptic ulcer or gastric cancer later in life. ${ }^{1}$ Non-invasive diagnostic tools are particularly useful in children as screening tests and for epidemiological studies, but their accuracy has to be tested against that of invasive tests in symptomatic patients before they are used in any particular population.

Of the non-invasive tests now available, serological testing is not accurate in young patients and the ${ }^{13} \mathrm{C}$ urea breath test is expensive. In 1998 an enzyme linked immunoassay (ELISA) (Premier-PlatinumHpSA, Meridian Diagnostics, Cincinnati, OH, USA) was approved by the Food and Drug Administration for both diagnosis in adult symptomatic patients, and monitoring the response to treatment. It is now commercially available, but its correlation with gastric infection has not been assessed in children. We evaluated its diagnostic accuracy against invasive tests in children undergoing endoscopy for clinical evaluation, and we determined the cut off values for the paediatric population.

\section{Patients, methods, and results}

Stool samples from 203 consecutive symptomatic children (97 male and 106 female; median age 7 (range 0.5 -15) years) undergoing endoscopy in six Italian paediatric units were collected at home by parents, frozen at $-20^{\circ} \mathrm{C}$, and sent to the coordinating centre (Novara). There they were tested according to the manufacturer's instructions, except that a disposable $10 \mu$ loop was used to improve reproducibility of sampling. Plates were read at $450 \mathrm{~nm}$ and $450 / 655 \mathrm{~nm}$ and were evaluated by direct visual reading without use of a plate reader (yellow microwell $=$ positive, white microwell $=$ negative). Stool testing was performed blind, without knowledge of the other test results. The cut off for chil- dren was determined with a receiver operating characteristic curve, confidence intervals were calculated by the exact method and likelihood ratios by CATmaker program (http://cebm.jr2.ox.ac.uk/docs/nomogram. html), and values were expressed as optical densities.

At endoscopy, biopsy specimens from the antrum and gastric body were taken for histology, microscopic identification of $H$ pylori (Giemsa staining), and urease testing. Patients were regarded as $H$ pylori positive if $H$ pylori was seen at histology and results of the urease test were positive, and as $H$ pylori negative when both tests gave negative results. When histology and the urease test gave conflicting results the results of the urea breath test or culture were used if available (urea breath test and culture were routinely performed in only two centres).

Altogether 146 children were $H$ pylori negative and $52 \mathrm{H}$ pylori positive (49 children had positive results of both the urease test and histology; in two, histology was negative but results of the urea breath test and culture were positive; and in one, the result of the urease test was negative but histology and the result of the urea breath test were positive); and five cases were considered indeterminate because histology and the result of the urease test conflicted and no other test was available.

The sensitivity of the immunoassay was high, but the specificity and accuracy decreased to $93 \%$ and $95 \%$ respectively when the cut off suggested by the manufacturer for adults ${ }^{23}$ was used and because a grey zone was used. With direct visual reading, sensitivity slightly decreased but specificity and accuracy significantly increased ( $\mathrm{P}=0.01$; table). When we used the cut off calculated from a receiver operating characteristic curve $(0.185$ at $450 \mathrm{~nm}$ and 0.135 at $450 / 655 \mathrm{~nm})$ false positive results were obtained in only two cases and the sensitivity was $98 \%$, specificity $99 \%$, accuracy $98 \%$, likelihood ratio positive 72 , and likelihood ratio negative 0.02 .

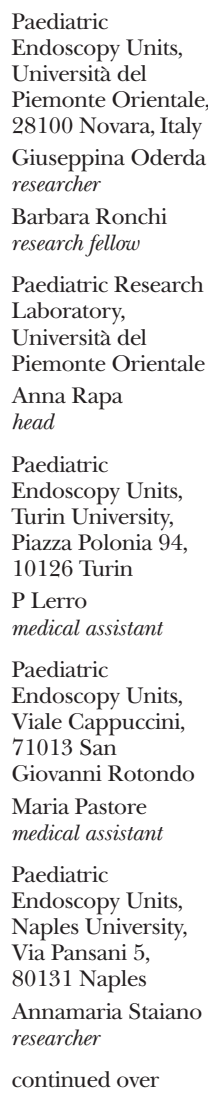

BMJ 2000;320:347-8

Test performance calculated according to different reading techniques (at $450 \mathrm{~nm}$ or double reading at $450 / 655 \mathrm{~nm}$ or by direct visual reading without use of plate reader) and to different cut off values as suggested by manufacturer

\begin{tabular}{|c|c|c|c|c|c|c|c|c|c|c|c|}
\hline \multirow{3}{*}{$\begin{array}{l}\text { Reading } \\
\text { technique }\end{array}$} & \multirow{3}{*}{$\begin{array}{l}\text { Cut off according } \\
\text { to manufacturer }\end{array}$} & \multicolumn{4}{|c|}{ Result } & \multirow{3}{*}{$\begin{array}{c}\text { Sensitivity (\%) } \\
(95 \% \mathrm{CI})\end{array}$} & \multirow{3}{*}{$\begin{array}{c}\text { Specificity (\%) } \\
(95 \% \mathrm{CI})\end{array}$} & \multirow{3}{*}{$\begin{array}{c}\text { Accuracy (\%) } \\
(95 \% \mathrm{CI})\end{array}$} & & & \multirow{3}{*}{$\begin{array}{l}\text { No of cases } \\
\text { in grey zone }\end{array}$} \\
\hline & & True & False & True & False & & & & \multicolumn{2}{|c|}{ Likelihood ratio $(95 \% \mathrm{Cl})$} & \\
\hline & & positive & negative & negative & positive & & & & Positive & Negative & \\
\hline $\begin{array}{l}\text { Reading at } \\
450 \mathrm{~nm}\end{array}$ & $\begin{array}{l}\text { Negative }<0.140 \text {, } \\
\text { grey zone } \\
0.140-0.160 \\
\text { positive }>0.160\end{array}$ & 52 & 0 & 136 & 10 & 100 (93.2 to 100$)$ & 93 (87.8 to 96.7$)$ & 95 (90.9 to 97.6$)$ & 15 (7.6 to 30.3$)$ & $0(0$ to 0.08$)$ & $\begin{array}{c}H \text { pylori } \\
\text { positive }=0 \dagger \\
H \text { pylori } \\
\text { negative }=4\end{array}$ \\
\hline $\begin{array}{l}\text { Reading at } \\
\quad 450 / 655 \mathrm{~nm}\end{array}$ & $\begin{array}{l}\text { Negative }<0.100 \text {, } \\
\text { grey zone } \\
0.100-0.120 \text {, } \\
\text { positive }>0.120\end{array}$ & 52 & 0 & 136 & 10 & $100(93.2$ to 100$)$ & 93 (87.8 to 96.7$)$ & 95 (90.9 to 97.6$)$ & 15 (7.6 to 30.3$)$ & $0(0$ to 0.08$)$ & $\begin{array}{c}H \text { pylori } \\
\text { positive }=0 \dagger \\
H \text { pylori } \\
\text { negative }=4\end{array}$ \\
\hline $\begin{array}{l}\text { Direct visual } \\
\text { reading }\end{array}$ & NA & 49 & 3 & 144 & 2 & 94 (84.1 to 98.8) & 99 (95.1 to 99.8$)$ & 97 (94.2 to 99.2) & $69(17.2$ to 494$)$ & 0.06 (0.01 to 0.17$)$ & NA \\
\hline
\end{tabular}

NA=Not applicable.

*According to manufacturer, these cases should be considered equivocal and second stool sample should be tested. The four $H$ pylori negative results are included in the10 false positives.

†According to invasive tests (histology plus urease test or culture). 
Paediatric

Endoscopy Units,

Parma University,

Via A Gramsci 14

43100 Parma

G L de'Angelis

researcher

Paediatric

Endoscopy Units,

Via T Campanella

88100 Catanzaro

P Strisciuglio

director of paediatric

department

Correspondence to: G Oderda oderda@ med.unipmn.it

\section{Comment}

The enzyme linked immunoassay that we assessed is highly accurate in diagnosing childhood $H$ pylori infection. The use of a grey zone may lower its accuracy, but the accuracy is satisfactory even with direct visual reading of the microwells without use of a plate reader; this makes it fairly cheap as a screening test (one determination cost is 22 euro (£14), half the average price of the urea breath test) and practical for epidemiological studies.

This study was approved by and conducted within the guidelines of the gastric disease section of the Italian Society for Paediatric Gastroenterology and Hepatology.

Contributors: GO designed and coordinated the study and wrote the article. AR and BR collected the data from each centre, analysed the faecal samples and did the statistical analysis. PL, MP, AS, GLde'A, and PS all participated in the discussion about the design of the study and approved the study proposal and the final draft; they also recruited all cases and collected data from patients from each centre, did endoscopy in children, and collected faecal samples to be sent to the coordinator centre. GO will act as guarantor for the paper.

Funding: Meridian Diagnostic Europe partially sponsored the study and provided free kits.

Competing interests: $\mathrm{GO}$ and $\mathrm{AR}$ have been reimbursed by Meridian Diagnostics, Europe (the manufacturer of HpSA) for attending a symposium on $H$ pylori and gastroduodenal disease in Helsinki.

Blaser MJ, Chyou PH, Nomura A. Age at establishment of Helicobacter pylori infection and gastric carcinoma, gastric ulcer, and duodenal ulce risk. Cancer Res 1995;5:562-5.

2 Makristathis A, Pasching E, Schutze K, Wimmer M, Rotter ML, Hirschl AM. Detection of Helicobacter pylori in stool specimens by PCR and antigen enzyme immunoassay. J Clin Microbiol 1998:36:2772-4

3 Vaira D, Malfertheiner P, Megraud F, Axon ATR, Deltenre M, Hirschl AM, et al, and European Helicobacter pylori HpSA Study Group. Diagnosis of Helicobacter pylori infection using a novel, non-invasive antigen based assay in a European multicentre study. Lancet 1999;354:30-3.

\title{
Effect of hormone replacement therapy on the pathological stage of breast cancer: population based, cross sectional study
}

\author{
Sheila Stallard, Janet C Litherland, Carolyn M Cordiner, Hilary M Dobson, W David George, \\ Elizabeth A Mallon, David Hole
}

University

Departments of Surgery and

Pathology, North Glasgow Hospitals University NHS Trust, Glasgow G11 6NT

Sheila Stallard staff grade surgeon Janet C Litherland consultant radiologist Carolyn M Cordiner consultant radiologist Hilary M Dobson consultant radiologist W David George professor of surgery Elizabeth A Mallon consultant pathologist

West of Scotland Cancer Surveillance Unit, University Department of Public Health, Glasgow G12 8RZ

David Hole

principal epidemiologist

Correspondence to: S Stallard dr37d@udcs. gla.ac.uk

BMJ 2000;320:348-9
Hormone replacement therapy is being used increasingly. Although it is known that the risk of developing breast cancer is slightly increased with long term use, ${ }^{1}$ hormone replacement does not seem to adversely affect mortality from breast cancer. ${ }^{2}$

Studies have suggested that users of hormone replacement who get breast cancer develop tumours with "favourable" pathological features compared with non-users. One study included women who had been detected at screening and women who had presented with symptoms, with more screen detected women in the study group (users) than in the controls (non-users). ${ }^{2}$ Another study compared type of tumour in users and non-users in a screen detected population alone $^{3}$ and showed that grade 1 , node negative tumours were more common in the users.

Women with breast cancer who have used hormone replacement, however, may be more likely to have a cancer that was missed at screening; we have shown that women who develop such cancers (interval cancers) within a year of screening are twice as likely to have been using hormone replacement when they were screened. ${ }^{4}$ We compared pathological features of tumours in both screen detected and interval cancers to assess whether previous use of hormone replacement therapy improves prognosis among women who develop breast cancer.

\section{Patients, methods, and results}

The study population comprised all 1130 women aged 50-64 years who underwent routine breast screening during May 1988 to December 1993 in the area of Scotland covered by the West of Scotland Breast Screening Unit and who either had a screen detected cancer or developed an interval cancer. Data on interval cancers were collected up to the end of 1996. Current use of hormone replacement (yes/no) had been recorded by radiographers at the time of screening and also at assessment for women with screen detected cancers. The case notes of half the women with interval cancers were reviewed to check whether use of hormone replacement at the time of presentation was the same as at their last screening. Seventeen women were excluded because use of hormone replacement was unknown, leaving 1113 patients for analysis.

Of the 815 women with screen detected cancers, $100(12.3 \%)$ were using hormone replacement when they were screened. Of the 298 women with interval cancer, 66 (22.1\%) were using hormone replacement; use at diagnosis was the same as at their previous screen. Of the total number of women studied, therefore, $166(14.9 \%)$ were using hormone replacement at the time they developed breast cancer.

We found no difference in type, size, or grade of tumour in users compared with non-users (table). Twenty four per cent of users developed well differentiated tumours (tubular, mucoid, and invasive ductal grade 1 cancers) compared with $22 \%$ of non-users. This equates to an odds ratio of 0.98 (95\% confidence interval 0.63 to 1.50$)$. Seventy seven per cent of users were node negative compared with $67 \%$ of non-users. There was no difference in mean tumour size (mean difference $0.25 \mathrm{~mm}(-2.02 \mathrm{~mm}$ to $2.53 \mathrm{~mm})$ ) in users compared with non-users. No difference was seen in the distribution of the Nottingham prognostic index ${ }^{5}$ between the two groups. Eight per cent of women using hormone replacement developed ductal carcinoma in situ compared with $15 \%$ of non-users. When 